\title{
High resolution multislice imaging of the fetal heart using iGRASP and MOG
}

\author{
Christopher Roy ${ }^{1,2^{*}}$, Mike Seed ${ }^{3}$, Christopher Macgowan ${ }^{1,2}$ \\ From 19th Annual SCMR Scientific Sessions \\ Los Angeles, CA, USA. 27-30 January 2016
}

\section{Background}

Multi-slice CINE MRI is an integral facet of postnatal cardiac examinations, but its application to the fetal heart is hampered by the lack of a fetal cardiac gating signal and the possibility of fetal motion. In this work, a method for reconstructing high spatial and temporal resolution multi-slice images of the fetal heart in a clinically acceptable scan time is presented. The proposed method combines metric optimized gating (MOG), a solution for fetal cardiac gating, with golden-angle radial sparse parallel MRI (iGRASP), a motion-robust acquisition and reconstruction scheme for highly undersampled data acquisitions [1,2].

\section{Methods}

Fetal acquisitions were performed using a 1.5T Avanto MRI system (Siemens, Germany). Ungated golden-angle radial spokes were acquired with scan parameters as follows: $\mathrm{TR} / \mathrm{TE}=5.7 / 2.7 \mathrm{~ms}, \mathrm{FA}=86^{\circ}$, field-of-view $=32 \times$ $32 \mathrm{~cm}^{2} 640$ spokes per slice, readout length 320 , voxel $=$ $1 \times 1 \times 4 \mathrm{~mm}^{3}$, scan length $=3.7$ seconds/slice, reconstructed temporal resolution $=23 \mathrm{~ms}$. For each slice, radial spokes were retrospectively sorted according to an estimation of the fetal cardiac cycle to create CINE frames of the beating fetal heart. The data were then iteratively resorted according the MOG method until a metric for image quality (entropy) was minimized. Each reconstructed CINE frame consisted of only 32 spokes, so a compressed sensing scheme (temporal total-variation) was used to suppress artifact [2]. Compared with the Nyquist sampling rate, the reconstructions corresponded to an acceleration rate of $\sim 16$. To cover the entire fetal heart, 20 slices were acquired with $50 \%$ overlap and the total scan time was 73 seconds.

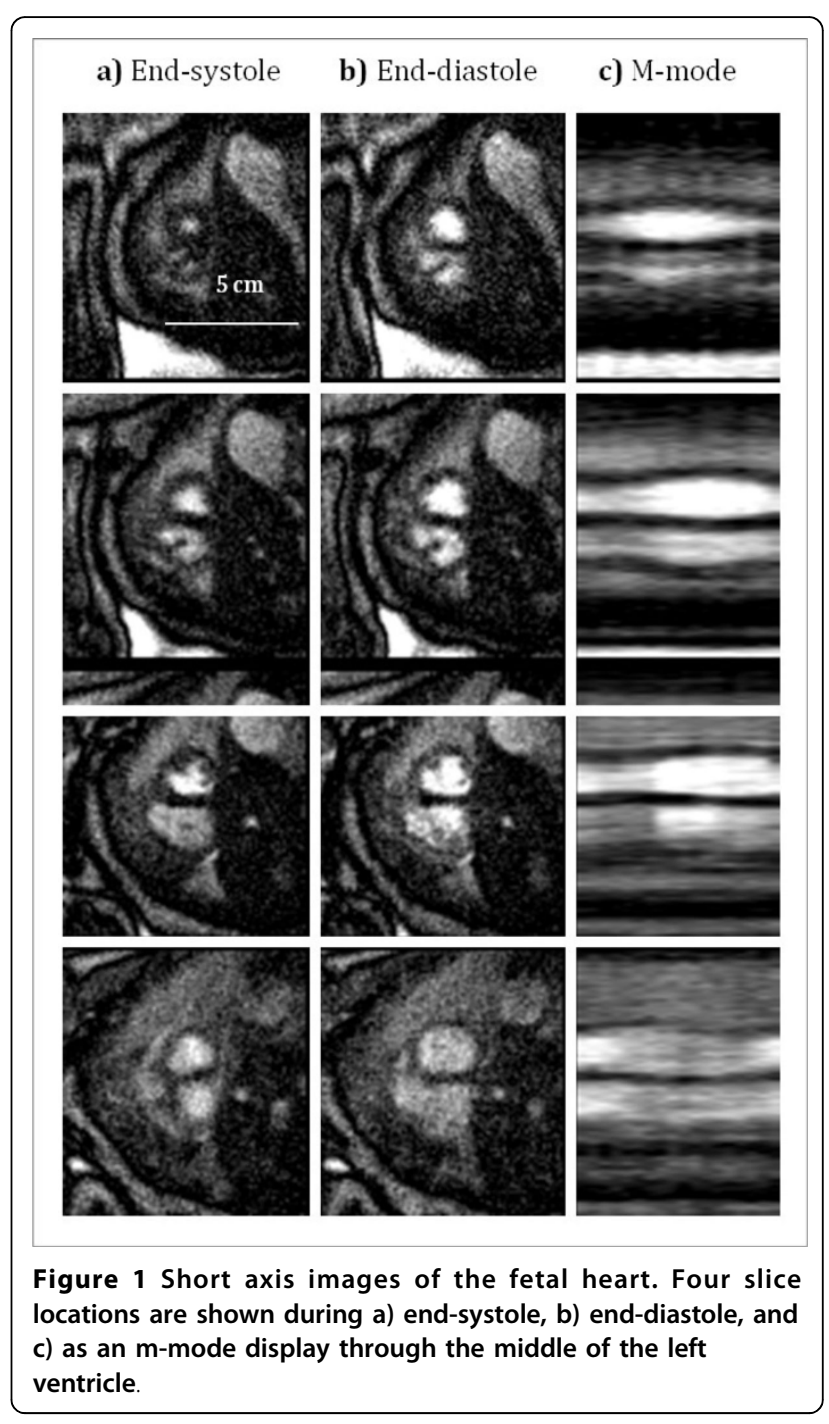

'Medical Biophysics, University of Toronto, Toronto, ON, Canada Full list of author information is available at the end of the article 


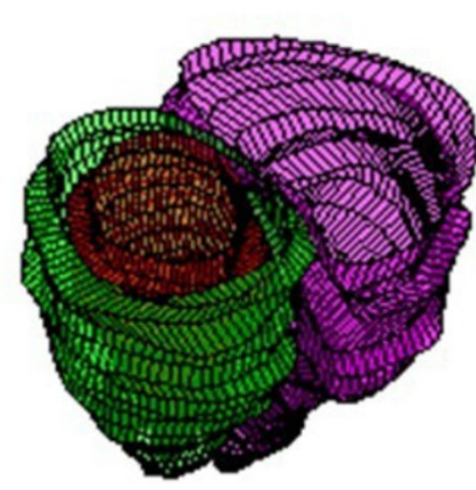

a) End-systole

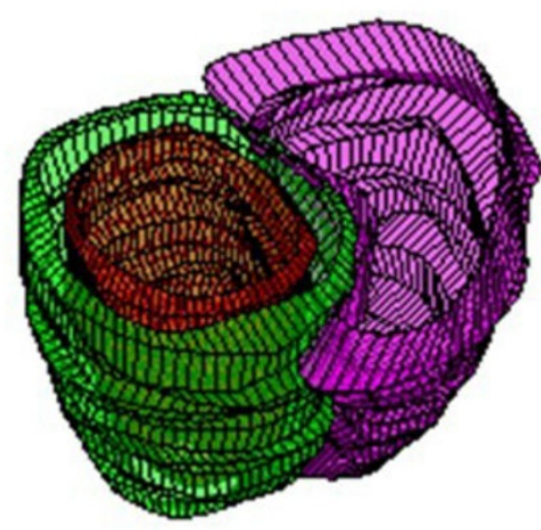

b) End-diastole

Figure 2 Ventricular volume reconstructions of multi-slice images of the fetal heart during a) end-systole and b) end-diastole.

\section{Results}

Figure 1 shows four representative short-axis views of the fetal heart at end-systole and end-diastole, and an M-mode display of the temporal profile through the ventricles. Small cardiac structures such as the left ventricle papillary muscles are well demonstrated. Normal myocardial contraction is visible in the M-mode display. Assessment of cardiac function was possible through 3D ventricular volume reconstructions of the multi-slice stack producing a measured left ventricle ejection fraction of $51 \%$. Figure 2 shows end-systolic and end-diastolic reconstructed volumes.

\section{Conclusions}

Using iGRASP and MOG, high resolution multi-slice imaging of the human fetal heart was possible in a clinically acceptable scan time (73 seconds) despite the absence of conventional cardiac gating. We were able to identify moving structures of interest during radial contraction, thus capturing normal fetal cardiac motion. Volumetric reconstruction of multi-slice data allowed for quantitative assessment of cardiac function.

\footnotetext{
Authors' details Hospital for Sick Children, Toronto, ON, Canada.

Published: 27 January 2016

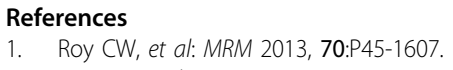

1. Roy CW, et al: MRM 2013, 70:P45-1607.

2. Feng L, et al: MRM 2014, 72(3):707-717.
}

${ }^{1}$ Medical Biophysics, University of Toronto, Toronto, ON, Canada. ${ }^{2}$ Physiology and Experimental Medicine, The Hospital for Sick Children, Toronto, ON, Canada. ${ }^{3}$ Division of Pediatric Cardiology and Diagnostic Imaging, The
doi:10.1186/1532-429X-18-S1-P44

Cite this article as: Roy et al:: High resolution multislice imaging of the fetal heart using iGRASP and MOG. Journal of Cardiovascular Magnetic Resonance 2016 18(Suppl 1):P44.
Submit your next manuscript to BioMed Central and take full advantage of:

- Convenient online submission

- Thorough peer review

- No space constraints or color figure charges

- Immediate publication on acceptance

- Inclusion in PubMed, CAS, Scopus and Google Scholar

- Research which is freely available for redistribution 